\title{
Research on the Maturity Evaluation of Human Resource Capability: A Construction of P-CMM Model
}

\author{
Khaled Mohammed Alqahtani ${ }^{1}$ \\ ${ }^{1}$ School of Business, Shaqra University, Riyadh, Saudi Arabia \\ Correspondence: Khaled Mohammed Alqahtani, School of Business, Shaqra University, 11662 Riyadh, P.O. Box \\ 88058, Saudi Arabia.
}

Received: June 30, 2019

Accepted: July 15, 2019

Online Published: July 17, 2019

doi:10.5430/ijba.v10n4p72

URL: https://doi.org/10.5430/ijba.v10n4p72

\begin{abstract}
The maturity of human resource has become a key factor in judging the outsourcing capability of enterprises. In this research, based on the analysis of previous research results, a analytic hierarchy process is used to build a P-CMM model. Specifically, the human resources outsourcing of Company A is selected as the empirical study object. According to the study results of Company A, the direction of human resources outsourcing is developed, and an improvement plan is formulated.
\end{abstract}

Keywords: People Capability Maturity Model (P-CMM), human resource outsourcing, Analytic Hierarchy Process (AHP), recommendations

\section{Introduction}

The People Capability Maturity Model (P-CMM) is of great significance in the research of human resource outsourcing of enterprises. The research on the maturity of human resource capability would help the human resource managers to find out the deficiencies in their current work, and thus find out the specific methods to improve their capabilities.

On the basis of previous literature of the P-CMM model, it can be seen that P-CMM is important to enhance human resource outsourcing capability. In addition, P-CMM plays a guiding role in the development of human resource outsourcing of enterprises. The ultimate goal of human resource outsourcing capability is to mobilize the enthusiasm and initiative of employees, improve the management level of enterprises in all aspects, and enhance the core competitiveness of enterprises. In this research, considering the example of Company A, an empirical study is carried out on the human resource outsourcing capability of enterprises through P-CMM model. Moreover, an optimized path for the human resource outsourcing management level is summarized.

\section{Construction of P-CMM Evaluation Model}

\subsection{Construction Steps of P-CMM}

(1) Determine the evaluation factors of capability maturity

Firstly, an evaluation system of People Capability Maturity Model is constructed, and six aspects in human resource management are selected to construct an evaluation system factor set. They are employee satisfaction index ratio, input training coefficient ratio, employee income comparison coefficient, income coefficient ratio, employee dynamic stability ratio and potential employee income coefficient ratio. The factor set $\mathrm{U}$ is: $\mathrm{U}=\{\mathrm{u} 1, \mathrm{u} 2, \ldots \mathrm{um}\}$.

The number of primary indicators contained in $U$ can be obtained by dividing subsets. The factor set $U=\{U 1, U 2, \ldots$ $\mathrm{Uk}, \ldots \mathrm{Um}\}$ is divided into $\mathrm{n}$ subsets according to the nature, $\mathrm{k}=1,2, \ldots, \mathrm{n}$.

(2) Calculation of relevant evaluation factors

Through specific calculation formula, relevant evaluation factors can be calculated, as shown in Table 1 below.

(3) The value corresponding to weight can be gained by analyzing the influence grade of every valuation factor. Every factor in factor set $U$ has different degree of importance, which is reflected by the weight set specifically. The corresponding weight ai $(\mathrm{i}=1,2, \ldots, \mathrm{m})$ is endowed to every factor ui $(\mathrm{i}=1,2, \ldots, \mathrm{m})$ to form a factor weight set $\mathrm{A}=\{\mathrm{a} 1$, $\mathrm{a} 2, \ldots, \mathrm{am}\}$. 


\subsection{Determination of Weight}

In practical application, Delphi method, expert scoring method, analytic hierarchy process, statistical analysis method, judgment matrix analysis method and other methods are often used to determine the weight coefficient. The methods of decision-making by subjective judgment include Delphi method and expert scoring method, but these two methods have certain defects. For example, they are lack of scientificity, which is easily influenced by existing experience, knowledge and personal subjective understanding. AHP expresses people's subjective judgment in quantitative form, which is a combination of quantitative and qualitative methods. Here, AHP is used to determine the weight.

Table 1. Calculation formula of relevant evaluation factors

\begin{tabular}{lc}
\hline \multicolumn{1}{c}{ Category } & Formula \\
\hline Employee dynamic stability ratio & $s l r=\frac{S_{L}}{S_{T}} \quad s l=\frac{s l r_{c}}{s l r_{b}} \quad q_{1}=1-s l$ \\
\hline Employee income comparison coefficient & $s c f=\frac{\overline{w_{s}}}{\overline{W_{S}}} \quad q_{2}=\frac{s c f_{c}}{s c f_{b}}$ \\
\hline Income coefficient & $s f=\frac{T(E V A)}{T(S)} \quad q_{3}=\frac{s f_{c}}{s f_{b}}$ \\
\hline Input training coefficient ratio & $t i f=\frac{I(T)}{T(S)} \quad q_{4}=\frac{t i f_{c}}{t i f_{b}}$ \\
\hline Satisfaction index ratio & $h f=\frac{T(S)}{E(S)} q_{5}=\frac{h f_{c}}{h f_{b}}$ \\
\hline Potential employee income coefficient ratio & $s g f=\frac{T\left(s_{g}\right)}{T(S)} q_{6}=\frac{s g f_{c}}{s g f_{b}}$ \\
\hline
\end{tabular}

AHP implements decision-making through four steps. Firstly, when the hierarchical structure of the system is established, the relationship between various factors in the system is analyzed; secondly, when the pairwise comparison judgment matrix is constructed, elements of the same level are compared pairwise according to the importance of one certain criterion in the previous level; thirdly, the relative weight of the criterion is determined and the element comparison judgment matrix is calculated; fourthly, the order is sorted according to the calculation results of each layer of elements on the system target synthesis weight.

\subsection{Comparison of Element Importance}

The hierarchical structure is formed by systematizing and the top-down dominant relationship. The elements decomposed from complex problems into different levels are grouped according to attributes, which is its constituent principle. The elements of the upper level can control the elements of the lower level, while the elements of the lower level can also control the elements of next level when they are controlled by the factors of the previous level.

(1) The determination of scale. In this study, the scale is integers between 1 and 9 and their reciprocal. The meaning of scale 1 to 9 is shown in Table 2 below.

Table 2. Meaning of Scale 1 to 9

\begin{tabular}{lll}
\hline S/N & Level of importance & Assignment \\
\hline 1 & Elements $i$ and $\mathrm{j}$ are of the same importance & 1 \\
2 & Element $\mathrm{i}$ is slightly more important than element $\mathrm{j}$ & 3 \\
3 & Element $\mathrm{i}$ is more important than element $\mathrm{j}$ & 5 \\
4 & Element $\mathrm{i}$ is much more important than element $\mathrm{j}$ & 7 \\
5 & Element $\mathrm{i}$ is absolutely more important than element $\mathrm{j}$. & 9
\end{tabular}


6

7

8

9
Element $\mathrm{j}$ is slightly more important than element $\mathrm{i} . \quad 13$

Element $\mathrm{j}$ is more important than element $\mathrm{i}$. 15

Element $\mathrm{j}$ is much more important than element $\mathrm{i} . \quad 17$

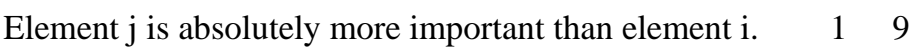

(2) The method of constructing the pairwise comparison judgment matrix

Many early-warning indexes a1, a2, ., an can be set in Criterion Ck. To obtain the relative importance values and construct the judgement rectangle $\mathrm{A}=$ (aij)nxn, the scale of the importance of indicators can be made based on Table 3 , where, aij refers to the importance values of element $\mathrm{i}$ and element $\mathrm{j}$ relative to the target. Where, the rectangle $\mathrm{A}$ has following natures: $a i j>0 ; a i j=1 / a i j(i \neq j) ; a i j=1(i, j=1,2, \ldots, n)$.

$$
A=\left[\begin{array}{cccc}
1 & a_{12} & \cdots & a_{1 n} \\
a_{21} & 1 & \cdots & a_{2 n} \\
\vdots & \vdots & \ddots & \vdots \\
a_{n 1} & a_{n 2} & \cdots & 1
\end{array}\right]=\left[\begin{array}{cccc}
1 & a_{12} & \cdots & a_{1 n} \\
1 / a_{12} & 1 & \cdots & a_{2 n} \\
\vdots & \vdots & \ddots & \vdots \\
1 / a_{1 n} & 1 / a_{2 n} & \cdots & 1
\end{array}\right]
$$

(3) The method of constructing comparison judgment matrix

Firstly, the calculation of judgment matrix is made for the product Mi of each row of elements:

$$
M_{i}=\prod_{j=1}^{n} a_{i j}, i=1,2, \cdots, n
$$

Secondly, the n-th root of Mi is calculated:

$$
\bar{W}_{i}=\sqrt[n]{M_{i}}
$$

Then, the vector $\bar{W}=\left[\bar{W}_{1}, \bar{W}_{2}, \cdots, \bar{W}_{N}\right]^{T}$ is normalized ${ }^{\bar{W}_{i} / \sum_{j=1}^{n} \bar{W}_{j}}$, so $\bar{W}=\left[\bar{W}_{1}, \bar{W}_{2}, \cdots, \bar{W}_{N}\right]^{T}$ is the eigenvector to be solved.

Finally, the maximum characteristic root $\lambda \max$ of the judgment matrix is calculated:

$$
\lambda_{\max }=\sum_{i=1}^{n} \frac{(A W)_{i}}{n W_{i}}
$$

Where, (AW)i represents the vector AW of the i-th element.

By checking the consistency of the judgment matrix, the eigenvector obtained from the above formula is the weight to be solved. Following formula is adopted:

$$
C R=\frac{C I}{R I}
$$

The index of the consistency judgment matrix is CI, ${ }^{C I}=\frac{\lambda_{\max }-n}{n-1}$, and the index of the random consistency judgment matrix is RI.

The average value of the results obtained through 500 samples is the value of matrix order 1-11 in RI value, while the average value obtained through 100 samples is RI value of $12-15$. RI value is directly proportional to matrix order value, as shown in Table 3 below.

Table 3. RI value comparison table

\begin{tabular}{lccccccccccccccc}
\hline $\mathrm{N}$ & 1 & 2 & 3 & 4 & 5 & 6 & 7 & 8 & 9 & 10 & 11 & 12 & 13 & 14 & 15 \\
\hline $\mathrm{RI}$ & 0 & 0 & 0.6 & 0.9 & 1.1 & 1.2 & 1.3 & 1.41 .5 & 1.5 & 1.5 & 1.5 & 1.6 & 1.6 & 1.6 \\
\hline
\end{tabular}


When $\mathrm{CR}=\mathrm{CI} / \mathrm{RI}<0.1$, the judgment matrix needs to be adjusted to convert the unsatisfactory consistency into satisfactory consistency.

Lastly, the synthesis weight of the system target can be obtained by calculating the elements of each layer.

\section{Empirical Analysis}

In this research, the foreign-funded enterprise-Company A is selected as the empirical research object, and empirical evaluation is conducted based on the P-CMM evaluation model.

\subsection{Human Resources Overview of Company A}

Company A has more than 200 employees, of whom 115 are males and 41 are females, accounting for $74 \%$ and $26 \%$ of total employees, respectively. The ratio of male and female is seriously unbalanced. The proportion of under-40-year-old and under-50-year-old personnel in the total is $58 \%$ and $78 \%$ respectively, with serious convergence in age structure. The Company has 93 employees who have worked for more than 15 years, accounting for $65 \%$. And there are 17 employees who have worked for less than 3 years, accounting for only $10.9 \%$. In addition, the company has 8 employees with senior titles, 59 employees with junior titles and 44 outside employees. The analysis of the current situation of Company A shows that this firm has not yet established a human resources outsourcing management system that meets its development needs. Company A currently lacks sufficient space for promotion and growth in its human resources outsourcing management. Moreover, it has not yet formed a good talent training environment, and lacks integrity and systematicness.

The Company did not realize that human resource outsourcing management has become an important resource in today's society, which still stays on the traditional concept of personnel management. The Company did not include talent work in the process of development and lacked strategically systematic thinking.

\subsection{Maturity Evaluation of Human Resource Outsourcing Management of Company A}

\subsubsection{Survey of Maturity Evaluation of Human Resource Outsourcing of Company A}

The evaluation of human resource outsourcing has two important effects on the human resource outsourcing management. On the one hand, through the inspection and feedback of the previous work, the improper allocation of human resources in the next recruitment and selection process can be avoided. And the probability of employing employees with low performance and poor working capability can be reduced. On the other hand, through effective performance management, human resource outsourcing can be redistributed. The evaluation of human resource maturity brings not only punishment and reward, but also guidance, standardization and encouragement. In this study, we can be found that the Company A lacks a clear, perfect and systematic evaluation system of human resource outsourcing maturity.

\subsubsection{Evaluation Results of Maturity of Human Resource Outsourcing of Company A}

80 questionnaires were distributed to Company A, and 68 were finally taken back, with an effective rate of $85 \%$. The selected capability evaluation results are obtained from the effective questionnaires, as shown in Table 4 and Table 5 below.

Table 4. Research results of human resource outsourcing capability of Company A

\begin{tabular}{|c|c|c|c|}
\hline Factor & Divisor & Ratio & Weight \\
\hline Flexible stcapability & Employee dynamic stcapability ratio & 0.7845 & 0.1437 \\
\hline Sustainable development capability & Salary coefficient ratio of growing employees & 0.7546 & 0.1246 \\
\hline Value creation capability & EVA salary coefficient ratio & 0.7458 & 0.2316 \\
\hline Study capability & Training weighted input coefficient ratio & 0.8578 & 0.1007 \\
\hline $\begin{array}{l}\text { Loyalty and sense of belonging } \\
\text { management capability }\end{array}$ & Employee happiness index ratio & 0.7165 & 0.1536 \\
\hline Overall competitive advantage & Competition coefficient ratio of employee salaries & 0.9054 & 0.2478 \\
\hline
\end{tabular}


Table 5. Evaluation results of human resource outsourcing capability of Company A

\begin{tabular}{|c|c|c|c|}
\hline Factor & Divisor & Weight Ratio & Evaluation \\
\hline Flexible stcapability & Employee dynamic stcapability ratio & 0.14370 .7845 & $\begin{array}{l}\text { Predictable } \\
\text { level }\end{array}$ \\
\hline Sustainable development capability & $\begin{array}{l}\text { Salary coefficient ratio of growing } \\
\text { employees }\end{array}$ & 0.12560 .7556 & $\begin{array}{l}\text { Predictable } \\
\text { level }\end{array}$ \\
\hline Value creation capability & EVA salary coefficient ratio & 0.23160 .7458 & $\begin{array}{l}\text { Predictable } \\
\text { level }\end{array}$ \\
\hline Study capability & Training weighted input coefficient ratio & 0.10170 .8588 & $\begin{array}{l}\text { Optimization } \\
\text { level }\end{array}$ \\
\hline $\begin{array}{l}\text { Loyalty and sense of belonging } \\
\text { management capability }\end{array}$ & Employee happiness index ratio & 0.15310 .7160 & $\begin{array}{l}\text { Predictable } \\
\text { level }\end{array}$ \\
\hline Overall competitive advantage & $\begin{array}{l}\text { Competition coefficient ratio of employee } \\
\text { salaries }\end{array}$ & 0.24730 .9069 & $\begin{array}{l}\text { Optimization } \\
\text { level }\end{array}$ \\
\hline Overall ratio & & 0.7992 & $\begin{array}{l}\text { Predictable } \\
\text { level }\end{array}$ \\
\hline
\end{tabular}

It can be seen that the score of the Company's human resource outsourcing management capability is in a predictable level. The Empirical results show that the score of human resource outsourcing capability exceeds the risk warning line of 0.75. Although there are still some problems in the Company's human resource outsourcing management, it is still at a normal level of development. In order to improve the business performance of the enterprise, the human resource outsourcing management capability should be further improved.

Judging from the six factors in the maturity evaluation model, the Company's competition coefficient ratio of employee salaries has reached the optimization level in the maturity level, with a specific value of 0.9069 , indicating that the Company pays more attention to enhancing its scientific and technological strength, technological innovation and new product development. The management mode is flexible. The Company's employees have high learning and discovery capability, and the training input coefficient is relatively high among the enterprises on an equal basis, with the data as high as 0.8588 . To maintain the learning and discovery capability of the Company's human resources, attention should be paid to the protection of professional talents and the wastage of professional talents should be reduced as much as possible. As can be seen from table 5, the employee happiness index of the Company is only 0.716, which is relatively low. This indicates that the Company cannot make employees have a strong sense of belonging. The reason for this phenomenon is that as a foreign-funded enterprise, Company A cannot effectively localize its cultural factors and living habits.

To sum up, Company A did not include talent work in its development process and lacked a set of complete and systematic evaluation system for human resource management outsourcing. By analyzing the evaluation results of the Company's human resource maturity, this research also finds that Company A lacks strategic and systematic management practice, scientific planning, salary system, scientific performance evaluation, etc. For example, the human resource outsourcing management capability of Company A is in the normal development level; the training input coefficient and employee salary competition coefficient ratio is relatively high, but the employee happiness index still needs to be continuously improved.

\section{Recommendations of Human Resource Outsourcing Management}

According to the empirical results, several suggestions are summarized to improve the management level of human resource outsourcing.

(1) The core strategy of human resource outsourcing management should be constructed.

As the cornerstone of an enterprise, talents play a decisive role in the sustainable development of the enterprise. Talents are the most potential investment and will become the core resources of the enterprises. In the process of development, enterprises should always put people first, set up enterprise development goals on the basis of training talents, and take the improvement of the maturity of human resource outsourcing as the key. Long-term enterprise development should be considered to welcome wise counselors and bold warriors. 
(2) The human resource outsourcing management should be continuously improved.

The enterprise development may be affected by a variety of factors, such as resource conditions and operating environment, which more or less hinder the improvement of human resources outsourcing capability. Enterprises cannot quickly improve their human resources outsourcing capabilities in a short period. Therefore, the active participation of individuals and the advanced programs of human resource outsourcing management are necessary. Moreover, the enforcement of various measures should be strengthened. There should be a long-term planning awareness in the human resource outsourcing management in enterprises.

The improvement of human resources outsourcing ability is a slow process, so the enterprise should seize key issues, start with the core issues, and formulate corresponding measures to solve the contradictions. Hence, the new management system can be adapted as soon as possible, the contradictions can be solved and the efficiency can be improved. Meanwhile, the construction of corresponding system should be improved and the corresponding business operations should be implemented. Besides, the focus of the new process should be concentrated, systematic analysis should be conducted, and the system should be updated with the times.

(3) Human resource outsourcing management should be implemented with P-CMM as the reference.

Enterprises should take P-CMM as a reference for human resource outsourcing management based on their own reality. Compared with other outsourcing management strategies, the problems pointed out and suggestions given by the P-CMM model are representative and referential. Five levels divided by P-CMM model analyzes the frequently occurring problems, and provides effective solutions.

\section{References}

Cai, J. X., Zhang, W., \& Lu, X. (2007). Research Problems of Evaluation Standard of Innovative Enterprise. Management Research on Science and Technology, 1(1), 40-42.

Curts, B., Hefley, E. W., \& Miller, A. S. (2001). People Capability Maturity Model. Addison--Wesley Professional, 665. https://doi.org/10.21236/ADA388676

Eisenharndt, K. M., \& Martin, J. A. (2000). Dynamic Capabilities: Why Are They. Strategic Management Journal, $21,183-201$.

Linders, B., \& Crosby, P. B. (2015). Quality Is Free: The Art of Making Quality Certain. New York: Mcgraw-Hill.

Maha, K., Osama, H., \& Curtis, B. (2014). Making It Personal. Software Development, 5(5), 321-346.

Teece, D., \& Pisano, G. (1994). The Dynamic Capabilities of Firms: An Introduction .Industrial and Corporate Change, 3(3), 104-121. https://doi.org/10.1093/icc/3.3.537-a

Treven, S., \& Mulej, M. A. (2005). Requisitely Holistic View of Human Resources Management in Innovative Enterprises. Cybernetics and Systems, 1, 45-63. https://doi.org/10.1080/01969720590887298

Wang, W. L., \& Wang, D. D. (2008). Innovative Enterprise: The Analysis of Characteristics of the Elements and Evaluation Index Design. Research Management, $223-226$. https://doi.org/10.1016/B978-1-84334-376-9.50019-4

$\mathrm{Xu}, \mathrm{Q}$. (2006). Construction on Innovative Country and the Age of Knowledge Economy. Jiangxi Social Science, 6 , 15-19.

Yang, D. Q., Ma, L., \& Xu, X. W. (2012). Study on the Maturity of People Capability in Innovative Enterprises. RISUS, São Paulo, 3(1), 53-60. https://doi.org/10.24212/2179-3565.2012v3i1p53-60

Zhang, M. (2002). Try to Discuss the Culture of Innovative Enterprise. Fujian Economic and Social, 3, 19-20. 